\title{
In Vitro Study on Antibacterial Activity of Aqueous Extract and Silver Nanoparticles of Andrographis paniculata
}

\author{
S. Jayashree* and G. Sangeetha Vani \\ Department of Microbiology, Ethiraj College for Women, Chennai, India \\ *Corresponding author
}

\section{A B S T R A C T}

\section{Keywords}

Silver nanoparticles, Andrographis paniculata, $\mathrm{UV}-\mathrm{Vis}$ spectrophotometer, Antimicrobial activity, Agar Well Diffusion method.

\section{Article Info}

Accepted:

15 April 2016

Available Online:

10 May 2016
Silver has been known for many centuries worldwide for its antimicrobial activity. It can be prepared by various methods like physical, chemical and biological method. The biological method includes synthesis of silver nanoparticles from plant extract which is also known as green synthesis. In this study, synthesis of silver nanoparticles (AgNPs) has been performed using stem extract of Andrographis paniculata by reducing aqueous silver nitrate. The silver nanoparticles are characterized by Ultraviolet-Visible (UV-Vis) spectrophotometer. Antimicrobial activity of the silver nanoparticles has been demonstrated by agar well diffusion method and it was found to be effective against Pseudomonas aeruginosa, Bacillus sps, Micrococcus sps and Staphylococcus aureus isolated from the water sample.

\section{Introduction}

Nanoparticles are particles ranging from $1 \mathrm{~nm}$ to $100 \mathrm{~nm}$. It can be synthesized using silver, gold, platinum, lead, zinc etc by two processes-Top down process which includes synthesis of nanoparticles by breaking down bulk particles by grinding, milling etc. and bottom up process is by self assembling atom to nuclei thereby forming nanoparticles (Kavitha et al., 2013).

Silver particles are composed of large amount of silver oxide due to their large ratio of surface-to-bulk silver atoms. It has numerous morphology constructed out of which sphere, diamond, octagonal and thin sheets are commonly used (Graf Christina et al., 2003). Cuboids, silver powder, silver colloids, hexagonal and triangular are various other shapes of silver. It is used to treat many diseases like diabetes, cancer etc.

Biological synthesis is commonly used method as it contains non-toxic ingredients. They are synthesized using living organisms like plant and microorganisms as reducing agent. It does not contain any stabilizer as it produces stable silver nanoparticles on its own. Temperature, silver ion concentration, $\mathrm{pH}$ are few factors influencing the synthesis of silver nanoparticles. The plant derived 
synthesis is commonly known as 'green synthesis' (Liu et al., 2009). The plant extract containing active bio molecules act as capping and compress the bulk silver oxide present in silver nitrate and make them into nanoparticles. This increases the efficacy of the silver against various pathogenic microorganisms causing harmful diseases.

Andrographis paniculata is an annual herbaceous plant. It is easily available and cost effective. The stems are quadrangular, slender and dark green. The extract contains large amount of active constituent known as andrographolide which is responsible for the bitter taste of leaves. It also contains hydroxyflavones and catechins, the phytochemicals (Dhiman Anju et al., 2012). It has various medicinal uses like treating flu and cold. It has wide application over treating digestive disorders, liver disorders, heart diseases, diabetes, rabies, tuberculosis, leprosy, syphilis, HIV- AIDS.

Silver nanoparticles have the ability to anchor to the bacterial cell wall and subsequently penetrate it, thereby causing structural changes in the cell membrane like the permeability of the cell membrane and death of the cell. There is formation of 'pits' on the cell surface and accumulation of the nanoparticles on it (Sondi et al., 2004). The formation of free radicals by the silver nanoparticles may be considered to be another mechanism by which the cells die. When in contact with the bacteria, these free radicals have the ability to damage the cell membrane and make it porous which can ultimately lead to cell death (Kim et al., 2007).

This study focuses on efficacy of aqueous extract and silver nanoparticles synthesized from stem of Andrographis paniculata against pathogens isolated from water sample.

\section{Materials and Methods}

\section{Collection of Water Sample}

The water sample was collected from Pallikarnai Lake in a sterile bottle. Micro organisms were isolated by spread plate technique. Based on the results obtained in the biochemical tests and the colony morphology on the agar plates, the pathogens were identified. Specific test was performed for species identification. The pure culture was maintained in agar slants for antimicrobial activity.

\section{Grinding of Plant Material}

The stem of Andrographis paniculata was taken and washed with clean water to remove the dust particles sticking onto the plant materials. It was then shade dried to remove the moisture and finely grounded to form powder. Then the powder was sieved and fine particles of the plant extract was obtained.

\section{Preparation of Plant Extract}

The plant extract was prepared by mixing $10 \mathrm{~g}$ of plant material with $100 \mathrm{ml}$ distilled water in a $250 \mathrm{ml}$ conical flask (El-Mahmood Muhammad Abubakar, 2009). It was incubated overnight, and then the solution was centrifuged for $15 \mathrm{~min}$ at room temperature with $7000 \mathrm{rpm}$. The supernatant was separated and filtered by membrane filtration technique.

\section{Synthesis of Silver Nanoparticles}

$5 \mathrm{ml}$ of plant extract of Andrographis paniculata was added to the brown amber bottle. To that $20 \mathrm{ml}$ of aqueous solution of $1 \mathrm{mM}$ Silver Nitrate was added. The amber bottle prevents the photo reduction of silver nanoparticles. The mixture was then 
adjusted to $\mathrm{pH} 8$ using $\mathrm{NH} 4 \mathrm{OH}$. It was agitated continuously for $24 \mathrm{hrs}$ at $80 \mathrm{rpm}$. It was characterized by UV-VIS spectrophotometer for the synthesis of silver nanoparticles.

\section{Characterization of Silver Nanoparticles}

\section{UV-VIS Spectrophotometer}

Distilled water was used as a blank. The solution was taken in the cuvette and the absorbance was observed in the range of 350 to $500 \mathrm{~nm}$.

\section{Antimicrobial Activity of Silver Nanoparticles}

The lawn culture was spread on the surface of Muller Hinton agar (Abishek et al., 2013). 2 wells were made on the agar using gel puncture. Silver nanoparticles of Andrographis paniculata and the plant extract of the same were poured into each well. It was incubated at $37^{\circ} \mathrm{C}$ for 24 hours. The two zones were compared and result was noted.

\section{Results and Discussion}

5 isolates obtained from water sample was cultured separately. The isolates were identified based on colony morphology, growth on selective media and biochemical's test results. The isolates were found to be Staphylococcus aureus, Staphylococcus sps, Micrococcus sps, Bacillus sps, and Pseudomonas aeruginosa.

The silver nanoparticles were synthesized (fig 1) and peak was observed at $420 \mathrm{~nm}$ using UV-Vis spectrophotometer (chart 1).

The antibacterial activity was performed with stem extract of $A$. paniculata and it was effective only against Pseudomonas aeruginosa (table 1) (fig $2 \&$ 3). Similar study was conducted by Pushpendra kumar et al., in 2013 using leaf extract of $A$. paniculata in which aqueous extract $A$. paniculata leaves does not show any sensitivity, only methanol extract have enough potential to kill drug resistant Gram positive bacteria.

Table.1 Antibacterial Activity of Aqueous Extract and Silver Nanoparticles (stem) of $A$. paniculata

\begin{tabular}{|l|l|l|}
\hline $\begin{array}{l}\text { NAME OF THE } \\
\text { ISOLATE }\end{array}$ & A. paniculata & Silver Nanoparticles \\
\hline S. aureus & No zone & $16 \mathrm{~mm}$ \\
\hline Staphylococcus sps & No zone & $6 \mathrm{~mm}$ \\
\hline Micrococcus sps & No zone & $15 \mathrm{~mm}$ \\
\hline Bacillus sps & No zone & $13 \mathrm{~mm}$ \\
\hline P. aeruginosa & $12 \mathrm{~mm}$ & $17 \mathrm{~mm}$ \\
\hline
\end{tabular}


Chart.1 Silver Nanoparticles synthesis of A. paniculata

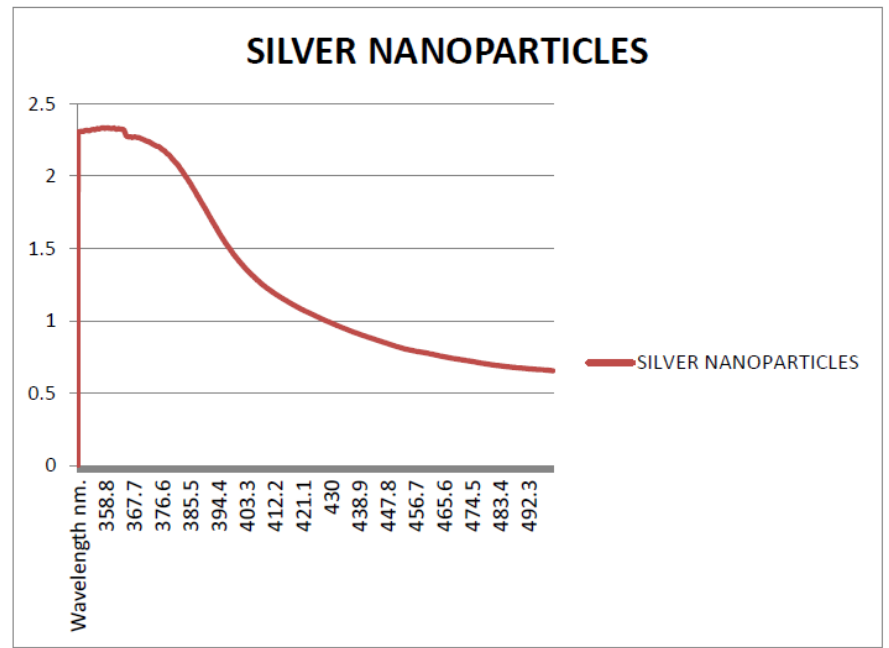

Chart.2 Anti Bacterial Activity of Plant Extract and Silver Nanoparticles of A. paniculata

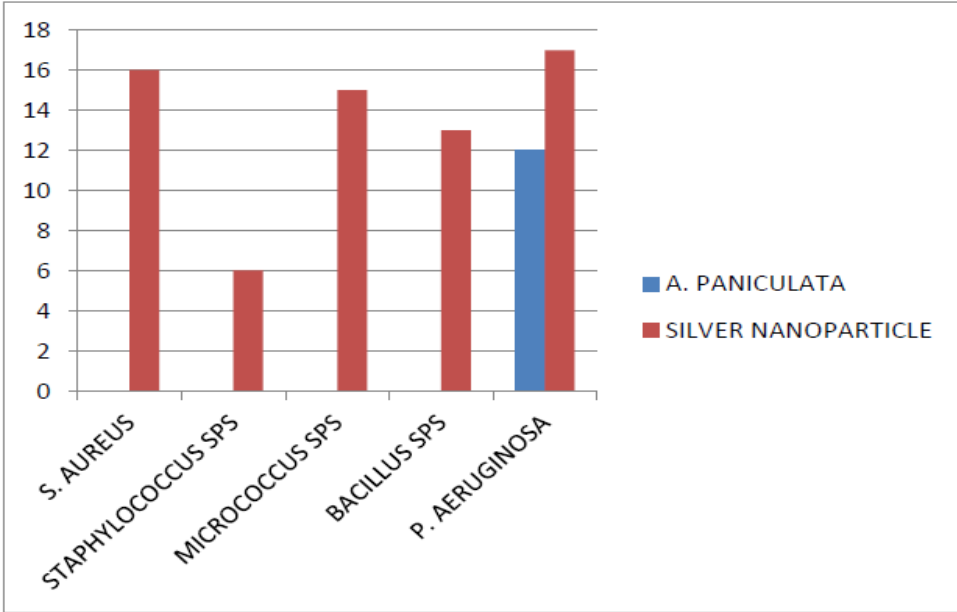

Fig.1 Synthesis of silver nanoparticles from A. paniculata

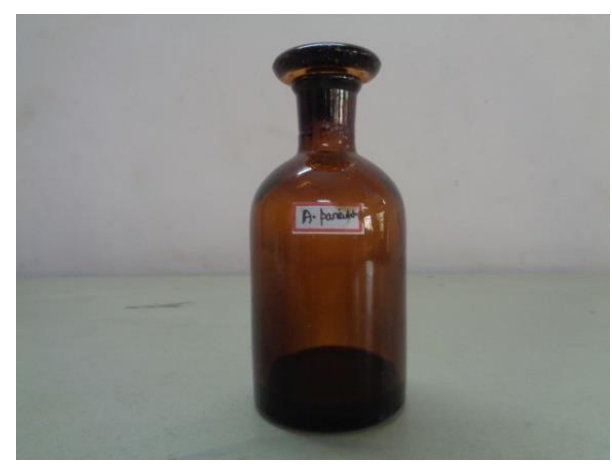


Fig.2 Antibacterial activity of silver nanoparticles against S. aureus, Staphylococcus sps and Micrococcus sps.

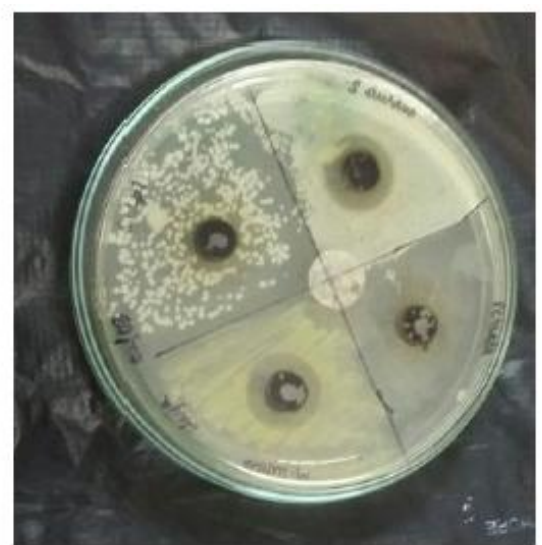

Fig.3 Comparison of silver nanoparticles and stem extract of A. paniculata
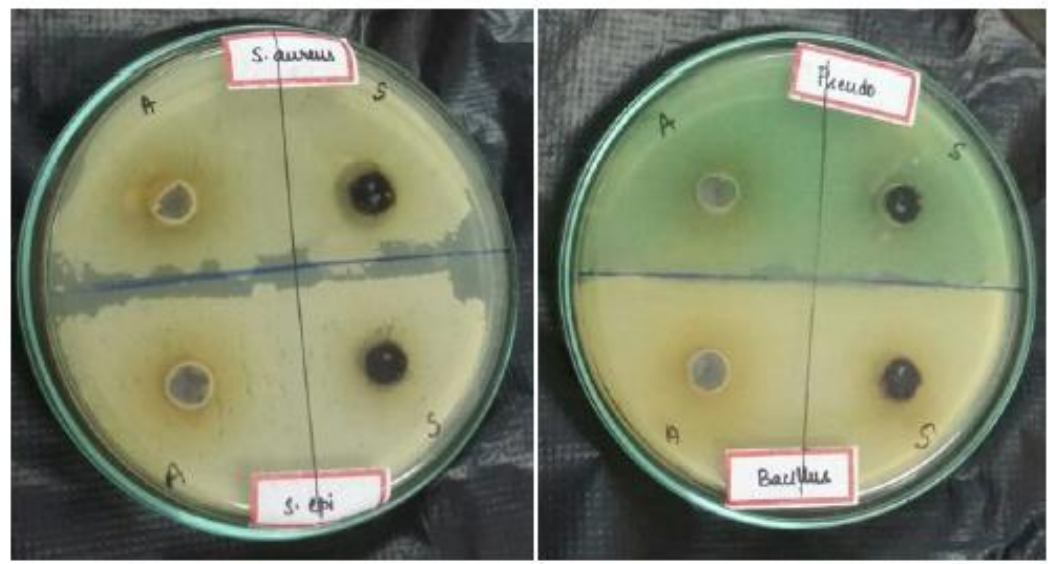

A- Andrographis paniculata S- Silver nanoparticles

Similar study was done by Padamata sai sudhakar et al., on synthesis of silver nanoparticles using the whole plant of $A$. paniculata and found Bacillus sps was less effective.

In this study, the silver nanoparticles of $A$. paniculata showed more antimicrobial activity compared to the aqueous stem extract of A. paniculata.

In conclusion, water is an essential source for all living organisms. We need around $50 \%$ of water for living a healthy life. Only $3 \%$ of fresh water is available on earth for consumption. Water fit for consumption is called potable water. Most water bodies are contaminated by various sources and lead to the scarcity of pure water. Intake of impure water may cause severe outbreaks.

Apart from consumption, water is also used in agriculture for irrigation purpose. Contamination of water damages the crops and the yield of the product. To overcome this, contaminated rivers and lakes need to be sterilized. Usage of chemicals to sterilize water may cause severe side effects. Thus the impure water can be purified by the silver nanoparticles synthesized by using plant extract. 
In this study, five isolates were collected from water sample and the antimicrobial activity was seen. It displays that $P$. aeruginosa is the most sensitive organisms to all plant extract. The least sensitivity was shown by Staphylococcus sps.

The aqueous stem extract of Andrographis paniculata is least sensitive against most organisms. The increasing drug resistant organisms are the threat to future generation which can be effectively treated by using herbal plants by synthesizing silver nanoparticles which acted upon most of the organisms. Thus the synthesized silver nanoparticles can be used to treat disease caused by pathogenic micro organisms. The silver nanoparticles can be impregnated on filter pads and it can be used to purify water (Narmatha et al., 2013). The present study unveils the importance of Andrographis paniculata in treating the water sample which in future helps in avoiding the use of chemicals for the treatment .

\section{References}

Abishek, S., Amruthaa Sundararaj. 2013. Green synthesis of Silver Nanoparticles from Psidium Guajava extract and Study of Anti-bacterial activity. Int. J. Frontiers in Sci. Technol.

Dhiman Anju, Goyal Jagnu, Sharma Kavita, Nanda Arun, Dhiman Sandeep. 2012. A review on medical prospective of Andrographis paniculata nees. $J$. Pharma. Scientific Innovation.

El-Mahmood Muhammad Abubakar. 2009. Antibacterial activity of crude extracts of Euphorbia hirta against some bacteria associated with enteric infections. J. Med. Plants Res., Vol.3: (7).p498-505.

Graf Christina, Vossen Dirk, L.J., Imhof Arnout, van Blaaderen Alfrons. 2003.
"A General Method to Coat Colloidal Particles with Silica". Langmuir, 19(17): 6693-6700.

Kavitha, K.S., Syed Baker, Rakshith, D., Kavitha, H.U., Yashwantha Rao, H.C., Harini, B.P., Satish, S. 2013. Plants as Green Source towards Synthesis of Nanoparticles. Int. Res. J. Biol. Sci., Vol.2(6): 66-76.

Kim, J.S., Kuk, E., Yu, K., Kim, J.H., Park, S.J., Lee, H.J., Kim, S.H., Park, Y.K., Park, Y.H., Hwang, C.Y., Kim, Y.K., Lee, Y.S., Jeong, D.H., Cho, M.H. 2007. Antimicrobial effects of silver nanoparticles. Nanomedicine, 3: p95101.

Liu, L., Wei, T., Guan, X., Zi, X., He, H., Dai, H. 2009. Size And Morphology Adjustment of PVP-Stabilized Silver and Gold Nanocrystals Synthesized by Hydrodynamic Assisted SelfAssembly. J. Phys. Chem., 113: p8595-8600.

Namratha, N., Monica, P.V. 2013. Synthesis of silver Nanoparticles using Azadirachta indica (Neem) extract and usage in water purification. Asian $J$. Pharm. Tech., Vol.3, Issue4: p170174.

Pushpendra Kumar Mishra, Rahul Kunwar Singh, Anamika Gupta, Adya Chaturvedi, Rahul Pandey, Shree Prakash Tiwari, Tribhuban Mohan Mohapatra. 2013. Antibacterial activity of Andrographis paniculata (Burm. f.) Wall ex Nees leaves against clinical pathogens. J. Pharm. Res., 7: p459-462.

Rajasekar, P., Priyadharshini, S., Rajarajeshwari, T., Shivashri, C. 2013. Bio-inspired Synthesis of Silver Nanoparticles Using Andrographis paniculata Whole Plant Extract and their Anti-microbial Activity over Pathogenic Microbes. Int. J. Res. Biomed. Biotechnol. 
Sondi, I., Salopek-Sondi, B. 2004. Silver nanoparticles as antimicrobial agent: a case study on E. coli as a model for Gram-negative bacteria. J. Colloid Interface Sci., p177-182.

Sulochana, S., Krishnamoorthy, P., Sivaranjani, K. 2012. Synthesis of silver nanoparticles using leaf extract of Andrographis paniculata. $J$. Pharmacol. Toxicol., 7: p251-258.

Wiley, B., Sun, Y., Xia, Y. 2007. Synthesis of Silver Nanostructures with Controlled Shapes and Properties. Accounts of Chemical Research Acc. Chem. Res., 40: p1067-1076.

\section{How to cite this article:}

Jayashree, S. and Sangeetha Vani, G. 2016. In Vitro Study on Antibacterial Activity of Aqueous Extract and Silver Nanoparticles of Andrographis paniculata. Int.J.Curr.Microbiol.App.Sci.5(5): 400-406. doi: http://dx.doi.org/10.20546/ijcmas.2016.505.041 